\title{
JEREMIAH 32 IN ITS HEBREW AND GREEK RECENSIONS ${ }^{1}$
}

\author{
Andrew G. Shead
}

It is widely accepted that the Masoretic Text and Septuagint Version of Jeremiah reflect different Vorlagen, but no final consensus has been reached on the relationship between them. This thesis enters the debate by undertaking a close study of the text of chapter 32 , with two questions constantly in mind. Firstly, can a given variant be traced back to the LXX Vorlage (henceforth LXXV), or it is to be seen as a creation of the translator? Secondly, where a variant is judged to arise from LXXV, can a decision be made as to whether it is prior or secondary to the reading of MT?

The first of these questions involves a consideration of translation technique in general, and frequently takes the discussion beyond the confines of chapter 32. It also raises the question of how decisions ought to be made when the evidence is equivocal. Does an overarching theory of translator literalism justify the conclusion in such cases that the more literal or consistent possibility is the right one, or should local considerations such as context and literary structure play a more dominant part? These questions occasionally involve inner-Greek variants and lead to engagements with Ziegler's edition of the Greek text. I conclude that although his work is generally reliable, he depends somewhat overmuch on the canon of the consistency of the translator.

In dealing with the second question - that of priority-I set to one side the prevailing theory that the Septuagint reflects an earlier edition of the book than MT, and examine each variant on its merits. While I have found a group of variants which lends itself to this theory (in particular, expansions of proper names, filiations, divine titles and the like), there is a second group which suggests extensive haplography in the LXXV tradition, and which I contend is much more extensive than generally recognised. A third group of variants is equivocal and

1 A.G. Shead, Jeremiah 32 in Its Hebrew and Greek Recensions: The Prophet, the Text, Its Translator and His Critics (unpublished Ph.D. thesis, University of Cambridge, 1998); supervisor Professor R.P. Gordon. 
depends for its interpretation on the application of extra-textual criteria, whether in the form of a general theory such as the one mentioned, or in the form of literary, exegetical or even literarycritical arguments for priority. It is at this point that the modern critic makes the deepest mark on the text, and there is a considerable danger that by applying his or her own canons of interpretive normality to the question, a text can be reconstructed which reflects both prophet, translator and critic in good measure.

In its assessment of the LXX as a translation, the present thesis treads a middle path between the claims that a variant Vorlage underlies every variation from MT, and that no 'grammatical' variant has a recoverable Vorlage. It is concluded that the translation does occasionally depart from strict literalism, whether on the grammatical, lexical or quantitative planes. Many of these departures are benign, often originating from differences in the structure of source and target languages. Yet there is a significant degree of exegetical rendering, much of it aimed at greater faithfulness to the shape and intent of the original. A significant number of 'compensatory renditions' were discovered, which seem to have been forced on the translator by corruptions in his exemplar. These cases tally well with probable haplographies identified in LXXV, forming an important corroboration of my earlier claim.

Recognising that no critic is without some guiding framework when it comes to exegesis, the thesis begins with a textlinguistic analysis of discourse markers in Jeremiah. I recognise that where the retroversion of variants is moderately objective, their evaluation is highly subjective, an exegetical rather than text-critical exercise. It is important, therefore, to establish a foundation upon which to build exegetical observations, and in the case of Jeremiah 32, some of the most difficult textual problems require decisions about the macrostructure of the discourse. I conclude that Jeremiah 32 consists of a narrative (vv. 1b-25) and subsequent discourse (vv. 26-44) held together by a framework of speech formulae which serve also to bind it into the larger story. The current trend to reclassify this chapter as a discourse addressed by its narrator to his (extra-textual) readers, and not a narrative within which characters speak to (intra-textual) addressees, betrays a failure to appreciate the way in which markers of discourse function within the book.

Both the study of discourse markers and the study of textual variants leads to the conclusion that the two recensions of Jeremiah are essentially similar, differing in extent but not in kind. Despite their 
essential similarity, however, attempts to characterise them as 'texts' rather than 'recensions' are unconvincing. While acknowledging the inherent uncertainties of any statement on the origins of the two recensions, the evidence of the present study points towards a nonlinear relationship in which MT is not a revision of LXXV, but each adds readings to a common text base. Their similarities suggest that the two recensions did not originate in widely separated times or circumstances, a conclusion which bears strong similarity to the 'editorial' theory of Eichhorn. 